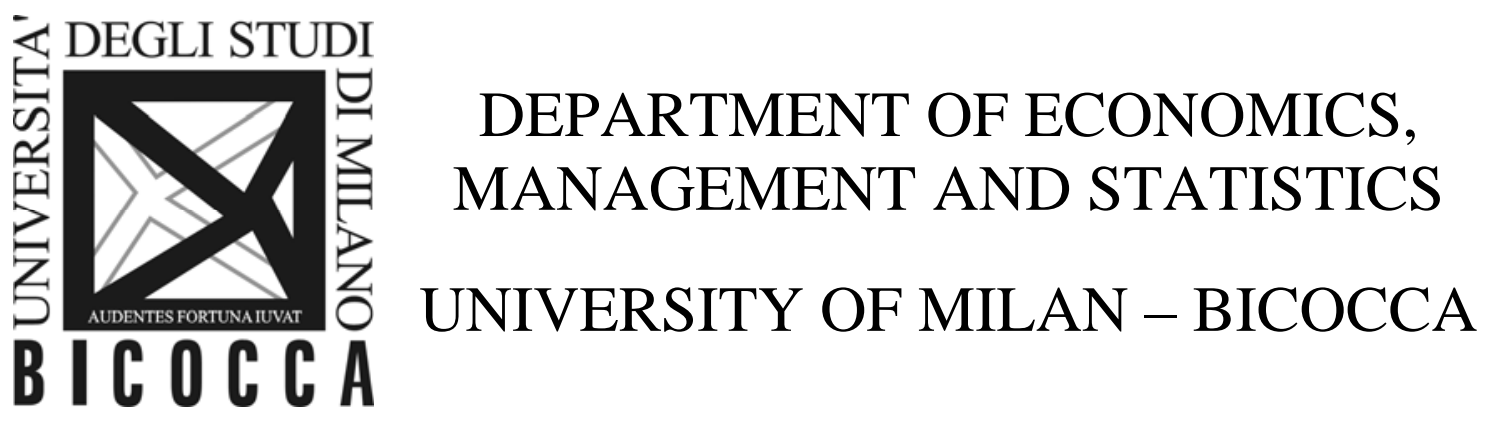

DEMS WORKING PAPER SERIES

Matching inefficiencies, labor market flexibility and local democracy in Spain

Ambra Poggi

No. 348 - July 2016

Dipartimento di Economia, Metodi Quantitativi e Strategie di Impresa Università degli Studi di Milano - Bicocca

http://dems.unimib.it/ 


\title{
Matching inefficiencies, labor market flexibility and local democracy in Spain
}

\author{
Ambra Poggi \\ University of Milan Bicocca and Laboratorio Revelli, Collegio Carlo Alberto \\ ambra.poggi@unimib.it
}

\begin{abstract}
By applying a stochastic production frontier approach to the matching process of unemployed and vacancies, this paper provides novel detailed insights into the process of job creation in Spain over the 2006-2012 period. The methodology produces estimates of the relative importance of demand and supply factors for the creation of new jobs, and of regional inefficiencies of job creation. This paper represents a first attempt to test whether a more flexible labour market as designed by the 2010 reform affects the matching efficiencies. We also investigate the possible link existing between local democracy (as factor influencing labour market governance) and inefficiency, handling endogeneity. Results suggest that the matching process was inefficient before the 2008 crisis. Efficiency increased during recession/rebound probably as consequence of policies aims to strengthen the economic system. In particular, the 2010 reform appears to have improved on average the matching efficiencies. Local democracy positively influences efficiency (and the effect is substantially higher when endogeneity in the inefficiency is handled). Despite these considerations, regional disparities in matching efficiencies persisted over time. Therefore, these results support the recommendation of further reducing matching inefficiencies before implementing policies aimed to increase the stock of vacancies at least in regions characterized by persistent inefficiencies.
\end{abstract}

This version: 15 July 2016

Key word: matching functions, regional labour market, stochastic frontier, democracy, endogeneity JEL classification: J64, A13, D63 


\section{Introduction}

The level of employment in Spain increased steadily during the 1990s and the first half of the 2000s. As a result, the unemployment rate was 8 per cent in 2007, the lowest since 1980. In the aftermath of the 2008 financial crisis, however, Spain experienced one of the sharpest contractions in employment among European countries. Between the first quarter of 2008 and the same quarter of 2011, the unemployment rate increased by 11.5 percentage points to reach 21.2 per cent (ILO, 2014). The economic rebound in 2010 and 2011 was much weaker in Spain than in other countries. The sovereign debt crisis that affected the country in 2011 further increased the unemployment rate that peaked at 27.1 per cent in the first quarter of 2013 (ILO, 2014). With intent to reduce unemployment, many different proposals of how legislation and governments could and should actively intervene have been publicly discussed. The aim of this paper is to investigate the matching process between job seekers and vacancies in order to offer appropriate policy suggestions for improving job creation (and, therefore, reducing unemployment). In particular, we measure inefficiencies in the matching process at regional level and discuss policies aimed at reducing such inefficiencies (e.g. policies increasing flexibility in the labour markets; policies improving labour market governance through the promotion of local democracy). In facts, when inefficiencies in the matching process between job seekers and vacancies are high, an increase in the stocks of vacancies would lead to fewer new matches than technically feasible. In such an environment, policies like the creation of subsidized vacancies might turn out to be prohibitively costly and counter-productive. Instead, policies that aim at reducing the inefficiencies would be advisable. On the other hand, in regions with highly efficient labour markets (given the stocks of unemployed and vacancies) the creation of new vacancies would indeed lead to additional job creation with high probability. In this context, the objective for the policymaker should be to increase the number of vacancies.

Since our aim is indicate to the policymaker which actions are advisable, we focus on the matching function, a useful tool that relates the flow of new hires observed monthly during the period 2006-2012 in Spain to the stock of vacancies and the number of unemployed job seekers. Following the previous literature (e.g. Warren, 1991; Fahr and Sunde, 2002; Ilmakunnas and Pesola, 2003; Coles and Petrongolo, 2008; Abid, 2011), we apply a stochastic production frontier approach to model the matching function. Thus, the matching function represents the maximum achievable number of job market matches (frontier production function), given the number of job seekers and vacancies. Labour market can deviate from it by having too few matches; in this case, labour markets present degrees of inefficiencies (deviations from the frontier) and the latter may be explained by observable factors characterizing the labour markets. Among the latter, we test whether a 
more flexible labour market as designed by the 2010 reform (RDL 10/2010) reduces regional inefficiencies. We also investigate another important determinant of inefficiencies: local democracy. In fact, the level of local democracy can influence the quality of labour market governance at the local level as well as the regional implementation of the labour market reform. Only a labour market supported by adequate laws, policies, institutional arrangements, industrial relations and labour administration services (including inspections for ensuring compliance with labour laws, vocational training and public employment services) can operate effectively. However, the level of local democracy can be endogenously determined. Therefore, following the new stochastic frontier methodology proposed by Karakaplan and Kutlu (2015a), we examine local democracy as one of the determinants of the matching inefficiencies while handling endogenity.

Our contribution to the literature is twofold. First, we offer fresh empirical evidence about the inefficiency of the matching process of unemployed job seekers and vacancies on the Spanish regional labor markets in a period characterized by two economic crisis. Second, investigates two important determinants of inefficiencies using a stochastic frontier approach: labour market flexibility and local democracy. In particular, we suggest the importance of local democracy as factor explaining regional disparities in matching efficiency. As far as we know, no previous studies have done it.

The structure of this paper is as follow. Section 2 illustrates the main characteristics of the Spanish labour markets during the economic crises. It also shortly describes the reforms implemented by the Spanish government and the importance of local democracy in shaping the labor market governance in Spain. Section 3 reviews the main literature on matching inefficiencies and introduces our approach for estimating the matching function. Section 4 gives information on data and describes the main variables. Section 5 presents estimation results. Section 6 concludes the paper.

\section{The Spanish labour markets during the economic crises (2008-2012)}

Following the steep contraction of GDP in 2008 - on par with that in other advanced economies - the economic rebound in 2010 and 2011 was much weaker in Spain than in other countries. For instance, while euro area countries grew on average by 1.8 per cent between 2010 and 2011, the rebound in economic activity in Spain was of limited duration and intensity, i.e. GDP grew on average by 0.4 per cent between the third quarters of 2010 and 2011. This left the Spanish economy in a rather vulnerable position when the second recessionary period hit Europe in late 2011. As a result, GDP fell by 2 per cent in 2011 (ILO, 2014)

The impact of the recession on the labour markets was extremely large. The contractions in the employment affected differently Spanish regions. Sala and Trivín (2013) observes the existence of less responsive regions in the North and North-West of Spain (Galicia, Asturias, Castile and Leon, Basque Country, Navarre, Aragon) with employment growth rates around $-2.5 \%$ in 2008-2012, and more volatile ones in the South and East part 
of Spain with employment growth rates between-3.3\%and-4.1\%. Madrid (also the Balearic Islands and to some extent Cantabria) was an exception with top employment performance simultaneously in good and bad times (employment growth rates around $-2.5 \%$ in 2008-2012).

Between the first quarter of 2008 and the same quarter of 2011, the unemployment rate increased by 11.5 percentage points to reach 21.2 per cent (ILO,2014) In general, unemployment remain high persistent over the crises years (Sala and Trivín, 2013). The increase in unemployment among low-educated individuals was considerably more pronounced in Spain than in most other EU member states. As the crisis erupted, temporary employment accounted for the bulk of job destruction, especially in those sectors where youth employment was comparatively more relevant. As a result, the youth unemployment rate doubled by the end of 2010 (ILO,2014). Finally, skills mismatch appeared more pronounced in Spain than in other European countries leading to additional obstacles to youths attempting to enter the labour market during the recession (ILO,2014).

Differences in unemployment across regions emerged and reinforced as consequences of the economic crises. These differences can to a large extent be explained by differences in the weight of construction or other housing related sectors (that are the sectors more severely affected by the 2008 crisis) across regions. These differences can be also attributed to both disparities in the respective regional equilibrium unemployment rates and the evolution of other key variables such as, for example, capital accumulation (Bande and Karanassou, 2009,2013a and 2013b). Finally, the existence of regional differences in unemployment was further aggravated by the lack of geographical mobility of workers, slowing the reallocation of workers from high to low unemployment regions and therefore hampering labour market adjustment overall (Wölfl and Mora-Sanguinetti, 2011).

In this context, the Government of Spain has implemented a number of measures to enhance employment quality and job creation (ILO,2014; Wölfl and Mora-Sanguinetti, 2011; Corral and Villarejo, 2009).

First, a new labour market reform package was introduced in September 2010 (RDL 10/2010) ${ }^{1}$ with the aims to improve labor market flexibility and reduce the labour market duality that characterizes the Spanish labour markets since the liberalization of the use of temporary contracts in 1984. The reform mainly reduced the upper range of dismissal costs for permanent contracts and smoothed the difference in dismissal costs between temporary and permanent contracts. In particular, the reform expanded the conditions under which a dismissal for objective reasons could be justified: it provided clearer and more precise wording of the causes for objective justified dismissals by including the case for economic, technical (introduction of new ways of production), organizational and production-related (temporary fall in demand) reasons. ${ }^{2}$ It also established a workers capital fund that can be used in cases of dismissal or transfer to another area or on reaching retirement. The fund reduces, therefore, the one-time costs of dismissal. The reform also facilitated the use of permanent contracts reducing the severance pay in the case of unjustified dismissal. Moreover, the reform

\footnotetext{
${ }^{1}$ Another labour market reform was adopted by the Spanish government in February 2012. Our period of study is $2 / 2006-2 / 2012$, therefore the 2012 reform is not relevant for our analysis.

${ }^{2}$ The reform made also possible the reductions of working hours for economic, technical, organizational and productionrelated reasons.
} 
reduced the attractiveness of temporary contracts through the reinforcement of employment protection legislation for temporary workers.

Second, Spain increased their expenditure on active labour market policies (e.g. training, public employment services and supported employment and rehabilitation policies) during the crisis years. In particular, the "Personal Employment Agreement" (2011) introduced some innovations in the design of active policies, as the personalized itineraries for unemployed people belonging to specific targets groups (e.g. those aged over 45). In 2011, however, the upward trend in expenditure on active policies was interrupted: the expenditure per unemployed individual decreased in the case of active policies, while it increased in the case of passive ones (e.g. unemployed related benefits). This suggests that in 2011 there were both a redesign of the active policies targets and a transfer of funds from active to passive policies.

Third, Spain puts some efforts in promoting job creations introducing, in 2011, training and apprenticeship contracts for young unemployed (18-25 years of age) without any professional qualifications. The contract duration was set between one and two years, with an option for a third year under certain circumstances. Some fiscal benefits ( 100 per cent reduction in social contributions for firms with fewer than 250 employees and 75 per cent reduction for those firms above the threshold) were granted to firms that hire workers aged 20 or more.

The above measures designed by the Government of Spain are indeed policies that can affect, and perhaps improving, the efficiency of the Spanish labour markets. However, local governments manage and design the placement services at the regional level as well as regional public employment services have the autonomy to design ALMPs. Spain has, in fact, a highly decentralized government system (Ahmad et al., 2008) and local governments are the main actors in the formulation and implementation of policies at the local level (Hernandez de Cos and Perez, 2012). Thus, local governments play a key role in enhancing employment quality and job creation at local level and in determining the quality of regional labour market governance. The local government is composed of 17 Autonomous Communities and two autonomous cities, 50 Provinces led by provincial councils indirectly elected by municipal councils and 8100 Municipalities led by a directly elected council (UNDESA, 2006; UCLG 2010). In addition to municipalities and provinces, there are other local entities that include islands, territories smaller than municipalities, mancomunidades (that are larger than municipalities and are voluntary entities aimed to carry out joint projects and provide common services), comarcas, metropolitan areas, and other municipality groupings (Gobierno de Espana, 2006).

Finally, note that differences in the levels of local democracy across local governments can lead to differences in regional labour market governance and policies implementation at local level. To better understand this idea, we need to define the concept of democracy. Beetham (1996) relates the level of democracy to the level of accountability of public officials, government responsiveness and representativeness. In particular, government responsiveness is achieved when governments take note systematically of the full range of public opinion in the formulation and implementation of low and policies, while representativeness is achieved when access to government and media is not channeled in favour of wealth or connection. 
According to this definition, differences in accountability, responsiveness and representativeness across local governments translates in differences in local democracy. The latter may lead to differences in the quality of labour market governance at the local level in terms of adequate laws, ALMPs, institutional arrangements, industrial relations and labour administration services (including inspections for ensuring compliance with labour laws, vocational training and public employment services). In this paper, we investigate the importance of local democracy in determining the efficiency of the regional labour markets during the economic crises, after controlling for the characteristics of the regional labour markets and the impact of the 2010 reform.

\section{Matching inefficiencies and the matching function}

The search and matching model (Mortensen and Pissarides, 1994; Pissarides 2000) has become the canonical framework to introduce equilibrium unemployment in macroeconomic models. One of its fundamental building blocks is the aggregate matching function that relates the flow of new hires to the stocks of vacancies and unemployment. The matching function can be seen as the aggregate production function of the labour markets: it is a convenient device that "partially captures a complex reality [...] with workers looking for the right job and firms looking for the right worker" (Blanchard and Diamond, 1989). The matching function summarizes a trading technology between agents who place advertisements, read newspapers and magazines, go to employment agencies, and mobilize local networks that eventually bring them together into productive matches. The key idea is that this complicated exchange process is summarized by a well-behaved function that gives the number of jobs formed at any moment in time in terms of the number of workers looking for jobs, the number of firms looking for workers, and a small number of other variables (see Petrongolo and Pissarides, 2001, for a detailed review).

Because of various frictions in the labour market, jobs and workers do not match instantaneously. The unemployed can find jobs and vacancies can filled only after a delay. In this case, we face "mismatch" between jobs and workers. The literature has suggested a variety of measures (e.g. Padoa Schioppa, 1991; Manacorda and Petrongolo, 2006; Layard, Nickell and Jackman, 2005; Barnichon and Figura, 2015) to capture the extent of misallocation of jobs and workers. Alternatively, it is possible to estimate directly the efficiency of the labour market in producing matches by a given level of job seekers and vacancies (Warren, 1991). In this paper, we follow this approach. In facts, if the process were inefficient, then, from a policy point of view, it would be important to know how inefficient matching on the labour market is, and what determines this inefficiency.

Fahr and Sunde (2002) provides insights into the process of job creation investigating the overall efficiency of the matching process. The findings indicate substantial differences in the efficiency of the matching 
process across occupations. Moreover, they suggest that inefficiencies in the matching process are determined by the composition of the labor market with respect to the age and education structure, as well as the current labour market conditions. Abid and Drine (2011) also investigates the determinants of the inefficient functioning of the market. Using Tunisian data, they find that persistence unemployment may be interpreted as the inefficiency of the matching process. They also find differences in structural factors across regions. The persistently high rate of unemployment is, thus, the result of not only excess labour supply but is also related to a shortfall between supply and demand. In particular, regional differences in the composition of the stock of job seekers such as age and educational structure, structure by gender, and level of urbanization, contribute significantly to explaining regional efficiency disparities. They also investigates the role of policy aims to promote more flexibility in determining the efficiency of the Tunisian labour market finding a negative impact.

Ibourk, Maillard, Perelman and Sneessens (2004) focuses the determinants of matching efficiency changes. Using 1990-1995 French data, they allow efficiency to depend on variables meant to capture workers and firms characteristics. The findings suggest that about $30 \%$ of the efficiency changes can be explained in terms of changes in firms and workers characteristics. They also find that regional differences in matching efficiency are fairly stable over time. Instead, Ilmakunnas and Pesola (2004), using regional panel data from Finland from 1988 to 1997, find evidence of cyclical efficiency changes concluding that since regional matching efficiencies are very much dependent on business cycle, general stabilization policies are likely to improve efficiency.

In this paper, we investigate some of the factors (e.g. the composition of the labor market, policy aims to promote more flexibility, business cycle) that may explain matching efficiency as suggested by the above literature. We also focus on local democracy as possible determinant of matching efficiency. As far as we know, local democracy has never been studied to explain regional differences in matching efficiency.

\section{The estimation of matching function}

The matching function described above can be represented by a mathematical relationship that describes the formation of mutually beneficial relationships (called "matches") over time. In the context of job formation, the matching function $\mathrm{m}($.) describes the number of matches formed between unemployed job seekers and vacant jobs. Specifically, the number $M$ of new hires (matches) is related to the number of unemployed workers, $U$, and job vacancies, $V$, in the following way

$$
M=m(U, V)
$$


where $m(U, V)$ is concave and increasing in $U$ and $V$ and $m(0, V)=m(U, 0)=0$. Assuming a Cobb-Douglas functional form ${ }^{3}$, eq. 1 can be write as

$$
M_{t}=A U_{t-1}^{\alpha} V_{t-1}^{\beta}
$$

In the empirical analyses, two issues have been analysed in detail. Firstly, $\alpha+\beta$ measures the returns to scale in the matching process. While standard theories relay on the assumption of constant returns to scale (e.g. Pissarides, 2000), increasing returns (Anderson and Brugess, 2000; Boeri and Burda, 1996; Van Ours, 1993) can be explained by more matches in thick markets, for example. Increasing returns imply also multiple unemployment equilibria (Blanchard and Diamont, 2001). Other authors also suggested decreasing returns (Hynninen, 2005; Kano and Ohta, 2005). Secondly, attention has been devoted to the constant A in eq. 2 . The literature often refer to this term as scale parameter or mismatch parameter. The scale interpretation emerges since changes in A imply changes in the number of matches (given $U$ and $V$ ). Mismatch refers to occupational, skill and regional mismatch of vacancies and job seekers, labour market institutions that affect the intensity of search, and the effectiveness of employment services. In particular, denoting the search intensity of worker by s and the intensity of job advertising of firms by a, the matching function can be written as $M_{t}=B(s U)^{\alpha}(a V)^{\beta}=B s^{\alpha} a^{\beta} U^{\alpha} V^{\beta}$ where the constant $\mathrm{A}$ is written as $A=B s^{\alpha} c^{\beta}$, which is positively related to the search intensity. Thus, search intensity have an influence on how efficiently the labour market works. Assuming regional panel data, the matching function is typically estimated in the form:

$$
\log M_{i t}=\mu_{i}+\alpha \log U_{i t}+\beta \log V_{i t}+X_{i t} \delta+\varepsilon_{i t}
$$

Where $i$ denotes regions, $t$ the time period, $\mu_{i}$ are fixed regional effects, the vector $X$ includes regional and labour force characteristics. From eq. 3, the estimated "efficiency" of the labour market is given by $A_{i t}=$ $\frac{M_{i t}}{U_{i t}^{\alpha} V_{i t}^{\beta}}=\exp \left(\tilde{\mu}_{i}+X_{i t} \tilde{\delta}\right)$.

However, it is not completely correct to call the constant A as "efficiency" parameter (Warren, 1991). According to the efficiency analysis (e.g. Coelli et al., 1998), the matching function $\mathrm{m}(\mathrm{U}, \mathrm{V})$ can be interpreted as the technology that bring jobs and unemployed workers together. Therefore, it can be defined as a matching frontier: an upper boundary to the possible number of matches that can be achieved with given number of unemployed and vacancies. In this context, the constant A can be interpret as total factor productivity (Ilmakunnas and Pesola, 2003) while the technical efficiency of matching is defined as the inverse of the maximum expansion of matches that is possible given $U$ and $V$. If the maximum is achieved the technical efficiency is equal to one, otherwise the technical efficiency is less than one (i.e. inefficiency

\footnotetext{
${ }^{3}$ The vast majority of empirical studies of the matching function assumes a Cobb-Douglas functional form (see Petrongolo and Pissarides, 2001, for a survey)
} 
emerges). In this context, the intensity of search and job advertising, determines the number of matches. Regions may deviate from the frontier when the search intensity, although optimal for the individual workers and the firms, is lower than in some other regions (Fahr and Sunde, 2002; Ilmakunnas and Pesola, 2003).

The stochastic frontier function can be specified as

$$
\log M_{i t}=\mu+\alpha \log U_{i t}+\beta \log V_{i t}+w_{i t}-v_{i t}
$$

where the error terms, $w_{i t}$, are iid $N\left(0, \sigma_{w}^{2}\right)$ distributed. The terms $v_{i t}$ follow the $N\left(X_{i t} \delta, \sigma_{v}^{2}\right)$ distribution truncated at zero (Battese and Coelli, 1993, 1995. Thus, $-v_{i t}$ obtains only negative values and provides estimates of the regional matching inefficiencies (Coelli et al., 1998). $X_{i t}$ is a vector of efficiency regressors and $\delta$ are coefficient to be estimated. The technical efficiencies are given by $\exp \left(-v_{i t}\right)$.

Endogeneity problems can arise in stochastic frontier models if the inefficiency term and the error term are correlated, or in particular, the determinants of the inefficiency can cause this correlation. Endogeneity in stochastic frontier model would lead to inconsistent parameter estimates, and hence, it need to be address properly. This would necessitate a proper instrumental variable approach and it is a relatively more difficult task in stochastic frontier analysis than in the standard regression models. Karakaplan and Kutlu (2015a) provide a methodology to deal with the endogeneity issues in stochastic frontier models allowing $v_{i t}$ and $w_{i t}$ to be dependent through observables that shape both distributions. We apply this methodology as appropriate.

Finally, the model in Eq. (4) can be extended to include a time-invariant regional-specific term intended to capture specific heterogeneity (Greene, 2005: "true fixed-effect model") and can be fit by maximum simulated likelihood method.

\section{Data and variables}

We estimate the matching function using a data set that combine monthly labour market data from the Spanish Public Employment Service (SEPE - Servicio Público de Empleo Estatal) and yearly data from the Spanish European Values Surveys (EVS).

The PESE data include information on vacancies that required the intermediation of the PESE to be filled (both the inflow and the outflow of job offers), registered job seekers (stock, inflow and outflows of job seekers and registred unemployed by individual attributes), and total hires.

Our dependent variable is the log of total hires registered during a certain month. Total hires refers to jobs filled by registered job seekers (with or without the intermediation of the PESE). The latter includes both 
registered unemployed individuals ${ }^{4}$ and other people registered to the PESE searching for jobs. As job seekers variable, we use the logarithm of the number of registered job seekers at the end of the previous month. Thus, our dependent variable is a flow variable, while the job seeker variable is a stock variable

As vacancy variable, we need a stock variable measuring the total vacancies at the end of the previous month. This information is more problematic to obtain for the following two reasons. First, starting from the finding that vacancies are normally filled in one month or less (Coles and Petrongolo, 2008), we need to proxy the vacancies stock with the logarithm of the inflow of vacancies registered the month before. Second, we do not have precise information about the monthly inflow of vacancies. Spanish law requires employers to notify job vacancies to the PESE and there are social security cost incentive to do so. However, we have information only on job offers in which firms notify the vacancies and the employment service seeks suitable workers (vacancies that required the intermediation of the PESE). The remaining vacancies are notifies only when they are filled (together with the name of the worker who is going to take the vacancy up) giving information on the total hires only. Therefore, we need to apply a "correction factor" to the monthly inflow of vacancies that required the intermediation of the PESE in order to obtain the total monthly inflow of vacancies. We use as correction factor the ratio between the jobs filled with the intermediation of the PESE and the total hires. Some variables are normally considered as factors influencing search intensity or the probability of being hired (Petrogolo and Pissarrides, 2001). The age structure of the labour force may affect matching efficiency if employers prefer younger workers or young unemployed people search harder. Since recurring and prolonged unemployed spells are less likely among educated workers, education should have a positive impact on unemployment outflow. Long term unemployment may lead to loss of skills and, therefore, these workers may be less likely to be hired. Using PESE and Eurostat data as appropriate, we include the following controls: the proportion of the labour force under the age of 25 (u25), the proportion of population with tertiary education(he), the proportion of unemployed with spells of unemployment longer than 1 year (uld). Finally, we control for time effects adding a dummy to take into account the 2008 and the 2011 crisis.

Of most interest are the following possible factors influencing search intensity or the probability of being hired: changes in labor market flexibility and local democracy. Thus, to assess the effect on matching efficiency of the 2010 labour market reform aimed to increase flexibility in the labour market, we include a dummy variable taking the value zero before the reform and one after the reform. We also include a measure of local democracy using information from the Spanish European Values Surveys (EVS). These surveys contain annual data with regional disaggregation at Nuts 2 level. ${ }^{5}$ Over the period of study, data are available only in years 2006, 2008, 2020 and 2012. EVS include information on how individuals think about family, work, religion, politics and society. In particular, we focus on the individual perceptions of local democracy.

\footnotetext{
${ }^{4}$ Unemployed individuals need to register to receive social benefits

${ }^{5}$ At Nuts 2 level, Spain is divided in 19 administrative regions.
} 
Individuals answer to the following question (on a scale 0-10): "How satisfied with the way democracy works in country?". Subjective feelings, expectations and reference points play indeed a role in determining individual answers. However, information on perceived local democracy obtained by individuals is aggregate at regional level: the level of local democracy registered in a certain region is the average level assessed by individuals living in the area. Positive subjective biases should cancel out negative subjective biases since in aggregate individuals are rational. In other words, we assume that informational anchors and bias of individuals are randomly distributed. Therefore, individual perceptions once aggregated at regional level represent a good proxy for the level of local democracy. Data are then merged with PESE data. In years where EVS data are not available, we refer to previous year data.

The final data set contains monthly observations for 52 administrative regions (Nuts3 level), amounting to a total of about 3800 monthly observations over the period 2/2006-2/2012. As shown in Table 1, during the boom (2/2006-12/2007) on average there are 57749 registered job seekers and 13104 estimated vacancies giving a hiring level of around 7574 employees. During the periods 2008-2012, the registered job seekers sharply increase while the estimated vacancies decrease. The table also reports on average the vacancies requiring the intermediation of the PESE and the workers hired with the intermediation of the PESE (about the $11 \%$ of the total hires during boom and 5\% during the 2011 recession). Figure 1 shows, on averages, substantial regional disparities in terms of vacancies, job seekers and total hires during the recession periods (1/2008-6/2009 and 7/2011-2/2012). In particular, the differences in the proportion of job seekers across regions suggests that labour market opportunities are associated with specific regional structural characteristics. Thus, considering variables that reflect the attributes of job seekers could help in explaining the role of frictions in the matching process.

Table 2 indicates a substantial increase in the number of job seekers have been unemployed for more than one year (from $22 \%$ to $43 \%$ ) and in the fraction of jobseekers that are aged less than 25 (from $18 \%$ to $49 \%$ ) when the economy turns down. At the same time, turnover rate for the job seekers decreases: the relevant monthly inflow/stock ratio decreases from 19\% during the boom to $13 \%$ in the 2011 crises. Furthermore, slightly more than $30 \%$ of the active population, on average, have higher education.

Substantial regional disparities are also observed in terms of (perceived) local democracy. See Figure 2. During the 2008 economic crises, there are both regions registering low levels of local democracy (e.g. Pais Vasco, Catalunya and Canarias Islands) and regions having extremely high level of local democracy (Castillala-Mancha, Melilla, Asturia, Cantabria and Aragon). However, the level of local democracy decreases on average over time. 


\section{Empirical findings}

In this section we present results of the estimation of the stochastic frontier model for 52 regional groups observed monthly over the period 2/2006 -2/2012. First, we present the overall results. Second, we explore cyclical variations and we test the impact of the 2010 labour market reform on the matching efficiencies. Third, we investigates local democracy as one of the determinants of the inefficiencies in job creation, handling endogeneity.

\subsection{The overall results}

The main estimation results are reported in Table 3. OLS and fixed effects estimates are reported as benchmark. The estimated coefficients for the elasticity of all matches with respect to unemployment and vacancies are significantly positive, with the unemployment elasticity being much larger than the vacancy elasticity. We find evidence supporting constant returns to scale only when we do not control for regional fixed effects. Once controlled for regional fixed effects (e.g. Model 4), we find evidence of decreasing returns to scale. In the latter case, the unemployment elasticity is just above 20 percent while the vacancy elasticity is about 6 percent.

The efficiency of job creation can be estimated as $\mathrm{E}(\exp (-\hat{\varepsilon}))$. We find that the observed number of matches are about $16 \%(=1-E(\exp (-\hat{\varepsilon}))$ lower than the maximum levels due to inefficiency when we do not control for regional fixed effects (Table 3, Model 2). Once controlled for regional fixed effects, the estimates for the share of variance of the dependent variable explained by inefficiencies reduces from 16 percent to 5 percent (Table 3, Model 4). Some standard determinants of the inefficiencies are considered: the fraction of the labour force under the age of 25 (u25), the proportion of population with tertiary education (he) and the proportion of unemployed with spells of unemployment longer than 1 year (uld). Both a higher fraction of young and of high educated people in a given area is associated with a significantly higher overall matching efficiency. Using these estimation results (Model 4), one can compare regions according to their efficiency of job creation, as done in Table 6. Some regions exhibit consistently extreme inefficiencies in comparison to all other regions. These regions are Baleares Islands (19\%) Ceuta (16\%) Ciudad Real, Cuenca (12\%), Albacete, Guadalajara and Toledo (11\%). In these regions where inefficiencies are high, an increase in the stocks of vacancies would lead to fewer new matches than technically feasible. Thus, policies that aim at reducing the inefficiencies would be advisable. On the contrary, in regions characterized by high efficiency (e.g. Madrid) policies aimed to increase the stock of vacancy would lead to additional job creation with high probability. 


\subsection{Cyclical variations}

Table 4 presents results for estimations of stochastic frontier model with fixed effects exploring cyclical variation. The idea is to investigate the process of job creation separately in periods of economic upward (from January 2006 to December 2007) and in periods of recession/rebound (from 1/2008 to 2/2012). ${ }^{6}$ During the boom, the elasticity of matches with respect to unemployed is, with a value of 64 percent, larger than that with respect to vacancies (4 percent). During the recession/rebound, the elasticity of matches with respect to unemployed reduces to $25 \%$, while the elasticity of matches with respect to vacancies increases to 9 percent. In both cases, we observe decreasing returns to scale. However, returns to scale are much lower during recession/rebound.

The estimates of the overall inefficiency of job creation is higher during the boom (21\%) than during recession/rebound (5\%). However, regional disparities in matching inefficiencies are larger during recession/rebound than during the boom (see Table 6). In Model 4c (Table 4), the specification of the inefficiency term is an extended version of the specification used above: it includes dummies for the economic crisis (dummy equal to one from 1/2008 to 6/2009 and from 7/2011 to 2/2012) and the 2010 labour market reform (dummy equal to one from September 2010). Economic crisis is positively correlated with inefficiency, while the 2010 reform of the labour market reduces overall inefficiencies in the regional matching process suggesting that a more flexible labour market helps the matching process.

\subsection{Local democracy as determinant of inefficiencies.}

In Table 5, we present estimates for a stochastic frontier model with fixed effects with local democracy included in the specification of the inefficiency term. The focus is on the recession/rebound. Model 5a and $5 c$ treat democracy as an exogenous variable, while Model $5 b$ and $5 d$ consider the possibility of endogeneity of local democracy. We instrument the level of local democracy with the following instrumental variable: the average level of local democracy registered in the other Spanish regions. Therefore, our instrument results high correlated with the endogenous variable since it capture perceptions of democracy at national level. However, the instrument is not influenced by regional shocks in the perception of democracy and, thus, should not affect job creation at regional level.

Under the endogenous assumption, the coefficients of local democracy is, in absolute value, larger than the corresponding coefficients under the exogenous hypothesis. This suggests a strong positive impact of local democracy on efficiency. It is also important to note that the significance of local democracy increases under the endogenous assumption. Instead, after endogeneity is addressed, the estimated coefficients for the

\footnotetext{
${ }^{6}$ Recession is from $1 / 2008$ to $6 / 2009$ and from $7 / 2011$ to $2 / 2012$. Rebound is from $7 / 2009$ to $6 / 2011$.
} 
elasticity of all matches with respect to unemployment and vacancies remain the same in essence. The estimated impact of the other determinants of the inefficiency remains also the same.

\section{Conclusions}

This paper has investigated the efficiency of the matching process of unemployed job seekers and vacancies. We apply a stochastic matching frontier framework to Spanish data, which are disaggregated by regions. This allows us to offer fresh empirical evidence on the relative importance of demand and supply factors in the job creation process and evaluate the matching efficiency of different regions. In particular, we provide some facts to the political discussion on the efficiency of the labour market during the economic crisis and the appropriateness of the 2010 reform. We also evaluate the role of local democracy in the matching process handling endogeneity concerns.

We find the following results. First, job creation was inefficient before the 2008 crisis. Efficiency increased during recession/rebound even if strong regional inefficiencies disparities persist. We can explain this result observing that, during recession/rebound, we register low reservation wages since a decrease in the vacancyunemployment ratio (due to few vacancies and large unemployment rates) increases the time it takes to find an alternative job. Low reservation wages, therefore, reduce the time it takes to find a job implying a more efficient matching process. Moreover, since another vacant job in the market tends to increase the time it takes to match all the other vacancies (increasing inefficiency), we can conclude that the existence of a limited number of vacancies (as observed during recession/rebound) also increases efficiency in the matching process. Furthermore, efficiency increased during recession/rebound probably also as consequence of policies aims to strengthen the economic system. However, inefficiencies strongly persist in some regions indicating structural differences across regional labour markets.

Second, a more flexible labour market as designed by the 2010 reform appears to improve on average the matching efficiencies. This result confirms the idea that in order to enhance productivity and the allocation of labour, it is advisable to reduce the strictness of employment protection regulation (e.g. ECB, 2002). Thus, the 2010 reform, reducing dismissal costs for permanent workers, increases the incentives for employment to adjust to cyclical and structural changes, thereby positively affecting productivity.

Third, we suggest the need to improve local democracy to achieve a more efficient matching process. In facts, our results show that local democracy appears to be positively related to efficiencies. Therefore, in regions characterized by high inefficiencies in the matching process, we can improve efficiency thought policies aimed to foster local democracy (e.g. accountability of public officials, government responsiveness and representativeness). In facts, the latter policies are able to foster efficiency in the matching process positively 
affecting the labour market governance at local level (e.g. institutional arrangements, industrial relations, labour administration services and the formulation and the implementation of active labour market policies).

Finally, note that our results support the recommendation of reducing matching inefficiencies before implementing policies aimed to increase the stock of vacancies at least in regions characterized by persistent inefficiencies. In facts, in regions where inefficiencies are high, policies aimed to create vacancies might turn out to be prohibitively costly and counter-productive. In these regions, policymakers should focus in first instance to reduce inefficiencies addressing both appropriate labour market reform and policies aimed to foster local democracy. However, as suggested by ECB (2002), other factors (not directly analysed in this paper) are also able to make the matching process more efficient as more flexible wages and increased wage differentiation, improved education, training and life-long learning, reforms of tax and benefit systems, working time flexibility, and measures to increase labour mobility. Thus, policies aimed to reduce inefficiencies should consider multiple factors to achieve the result.

\section{References}

Ahmad, E., Brosio, G. and V. Tanzi. (2008) "IMF Working Paper, Local Service Provision in Selected OECD Countries: Do Centralized Operations Work Better?", International Monetary Fund

Anderson, P. and Brugess, S. (2000) "Empirical matching functions. Estimation and interpretation using disaggregate data", Review of Economics and Statistics 82: 93-102

Bande, R. and M. Karanassou (2009): "Labour market flexibility and regional unemployment rate dynamics: Spain 1980-1995",Papers in Regional Science, 88(1), pp. 181-207.

Bande, R. and M. Karanassou (2013a): "The NRU and the Evolution of Regional Disparities in Spanish Unemployment", Urban Studies, 50(10), pp. 2044-2062.

Bande, R. and M. Karanassou (2013b): "Spanish Regional Unemployment Revisited: The Role of Capital Accumulation", Regional Studies, forthcoming

Barnichon, R. and Figura, A. (2015) "Labor market heterogeneity and the aggregate matching function" American Economic Journal: Macroeconomics, American Economic Association, vol. 7(4), pages 22249, October.

Battese, G. E. and Coelli, T. J. (1993). A stochastic frontier production function incorporating a model for technical inefficiency effects. University of New England Working papers, No. 69.

Battese, G. E. and Coelli, T. J. (1995). A model for technical inefficiency effects in a stochastic frontier production function for panel data. Empirical Economics, 20(2), 325-332

Beetham, D. (1996) "Theorising Democracy and Local Government", in King, D. \& Stoker, G. "Rethinking Local Democracy", London: Macmillan, 28-49

Blanchard, O.J. and Diamond, P. (1989) The Beveridge curve, Brooking Papers on Economic Activity, 1, 1-60

Boeri T., Burda M., 1996., "Active labour market policies, job matching and the Czech miracle", European Economic Review, vol. 40, pp. 805-817 
Burda, M. and Profit, S. (1996) "Matching across Space: Evidence on mobility in Czech Republic", Labour Economics 3: 255-278;

Burgess S. and Profit, S. (2001) "Externalities in the matching of workers and firms in Britain", Journal of Labour Economics, 18: 473-502

Coelli T., Rao D. S. P. and Battese G. E. (1998) An Introduction to Efficiency and Productivity Analysis, Boston: Kluwer

ECB (2002) "Labour market mismatches in euro area countries", the European Central Bank

Fahr, R. and Sunde U (2002) "Estimations of Occupational and Regional atching Efficiencies Using Stochastic Production Frontier Models", IZA DP No. 552

Gobierno de Espana (2006) “Local Government in Spain”, Ministerio De Administratciones Publicas

Greene, W. (2005) "Reconsidering heterogeneity in panel data estimators of the stochastic frontier model", Journal of Econometrics 126, 269-303

Hernandez de Cos, P. and J. Perez. (2012) "Sub-national public debt in Spain: political economy issues and the role of fiscal rules and decentralization", European Commission

Hynninen, S-M2005. "Labour market status of job seekers in regional matching processes," ERSA conference papers ersa05p499, European Regional Science Association.

Ibourk, A., B. Maillard, S. Perelman, and H. R. Sneessens (2004): "The Matching Efficiency of Regional Labour Markets: A Stochastic Production Frontier Estimation, France 1990-1995," Empirica, 2004, 31 (1), 125

Ilmakunnas, P. and Pesola, H. (2003) "Regional Labour Market Matching Functions and Efficienc Analysis", Labour 17 (3) 413-437

ILO (2014) "Spain: growth with jobs", International Labour Office, CH-1211 Geneva 22, Switzerland

Jackman, R., R. Layard, and S. Savouri (1991): Mismatch: A Framework for Thought. Cambridge University Press, Cambridge U.K.

Kano S., Ohta A M., 2005., "Estimating a matching function and regional matching efficiencies", Japan and the World Economy, vol. 17, pp. 25-41

Karakaplan, Mustafa U. (2015b) "sfkk: Stata Module for Endogenous Stochastic Frontier Models in the Style of Karakaplan and Kutlu (2015)", mimeo

Karakaplan, Mustafa U. and Kutlu, Levent (2015a) "Consolidation Policies and Saving Reversals", SSRN paper

Layard R., S. Nickell, and R. Jackman. Unemployment: Macroeconomic Performance and the Labour Market, 2nd Edition, Oxford University Press, 2005.

Manacorda, M. and Petrongolo, B. (2006) "Regional mismatch and unemployment: theory and evidence from Italy, 1977-1998”, J Popul Econ 19:137-162

Mortensen, D and C. Pissarides. Job Creation and Job Destruction in the Theory of Unemployment, Review of Economic Studies, 61, 397-415, 1994

Padoa Schioppa, F. Mismatch and Labor Mobility, Cambridge, Cambridge University Press, 1991 
Petrongolo, B. and C. Pissarides. Looking into the black box: A survey of the matching function, Journal of Economic Literature, 39: 390-431, 2001

Pissarides, C. Equilibrium Unemployment Theory, 2nd ed, MIT Press, 2000

Sala, H. and P. Trivín (2013) "Labour Market Dynamics in Spanish Regions: Evaluating Asymmetries in Troublesome Times" IZA Discussion Paper No.77 46

UCLG, 2008. “Country Profile: Spain”, United Cities and Local Governments, mimeo

UNDESA, 2006. "Kingdom of Spain Public Administration Country Profile", United Nations Department of Economic and Social Affairs, mimeo

Van Ours, J.C. (1991) The efficiency of the Dutch labour market in matching unemployment and vacancies, De Economist, 139, 3, 358-78

Warren, R. S. (1991): “The Estimation of Frictional Unemployment: A Stochastic Frontier Approach,” Review of Economics and Statistics , 73(2), 373-377

Wölfl, A. and J. S. Mora-Sanguinetti (2011), "Reforming the Labour Market in Spain", OECD Economics Department Working Papers, No. 845, OECD Publishing 
Figure 1. Regional characteristics (average values during recession periods)
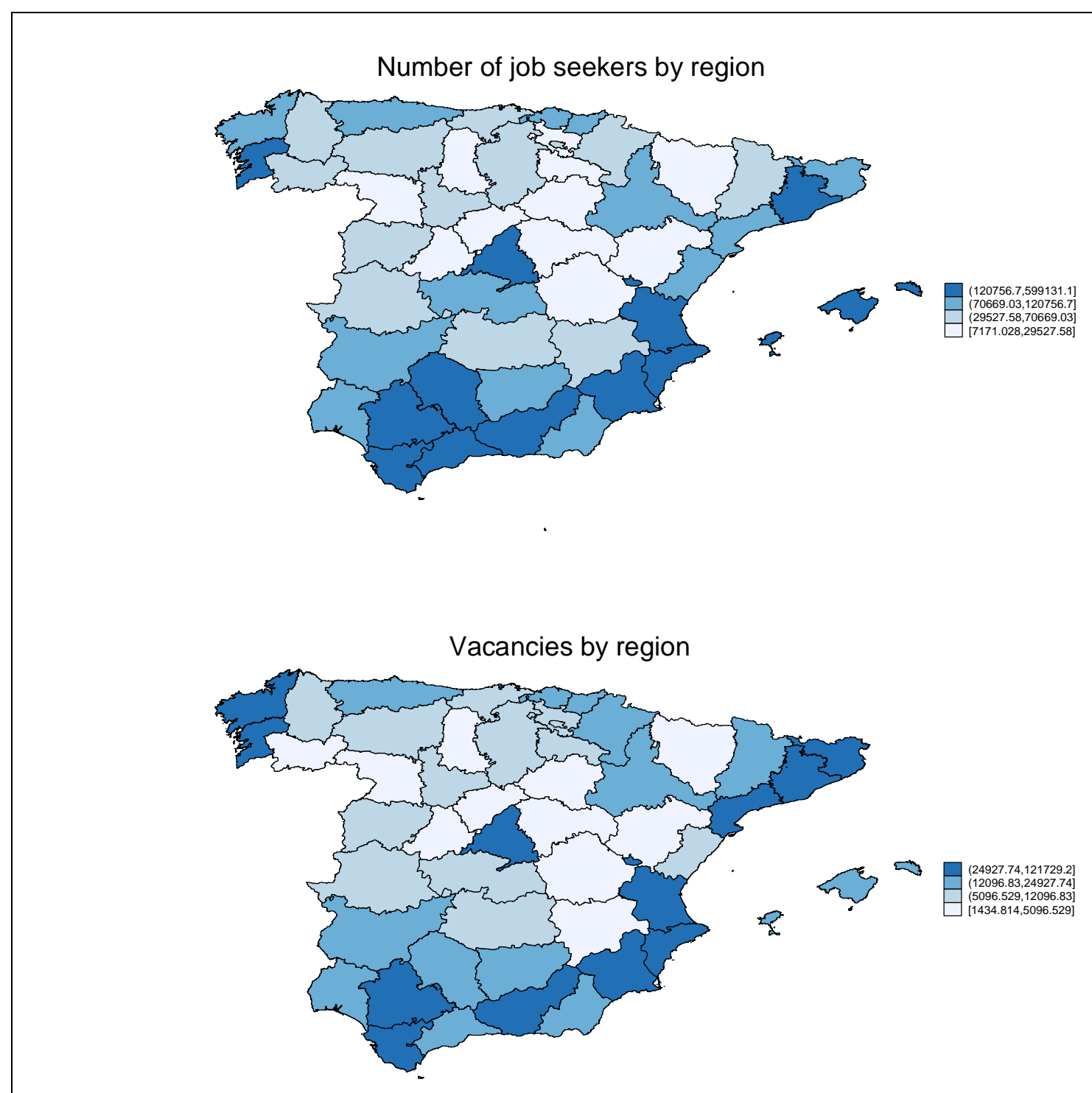

Hiring by region

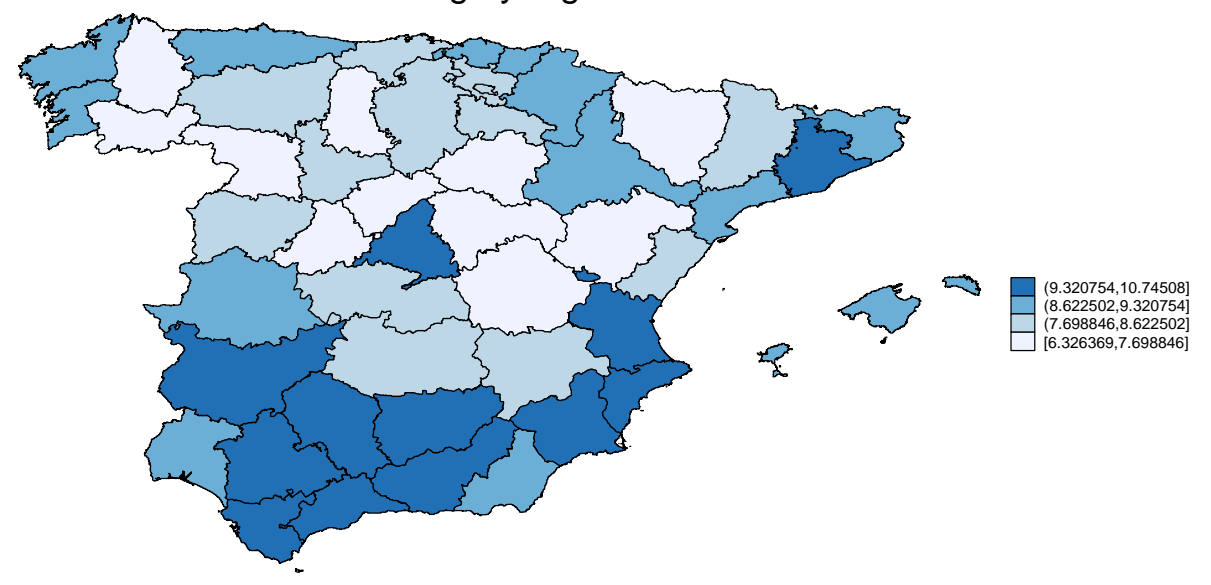


Figure 2. Local democracy (average values)

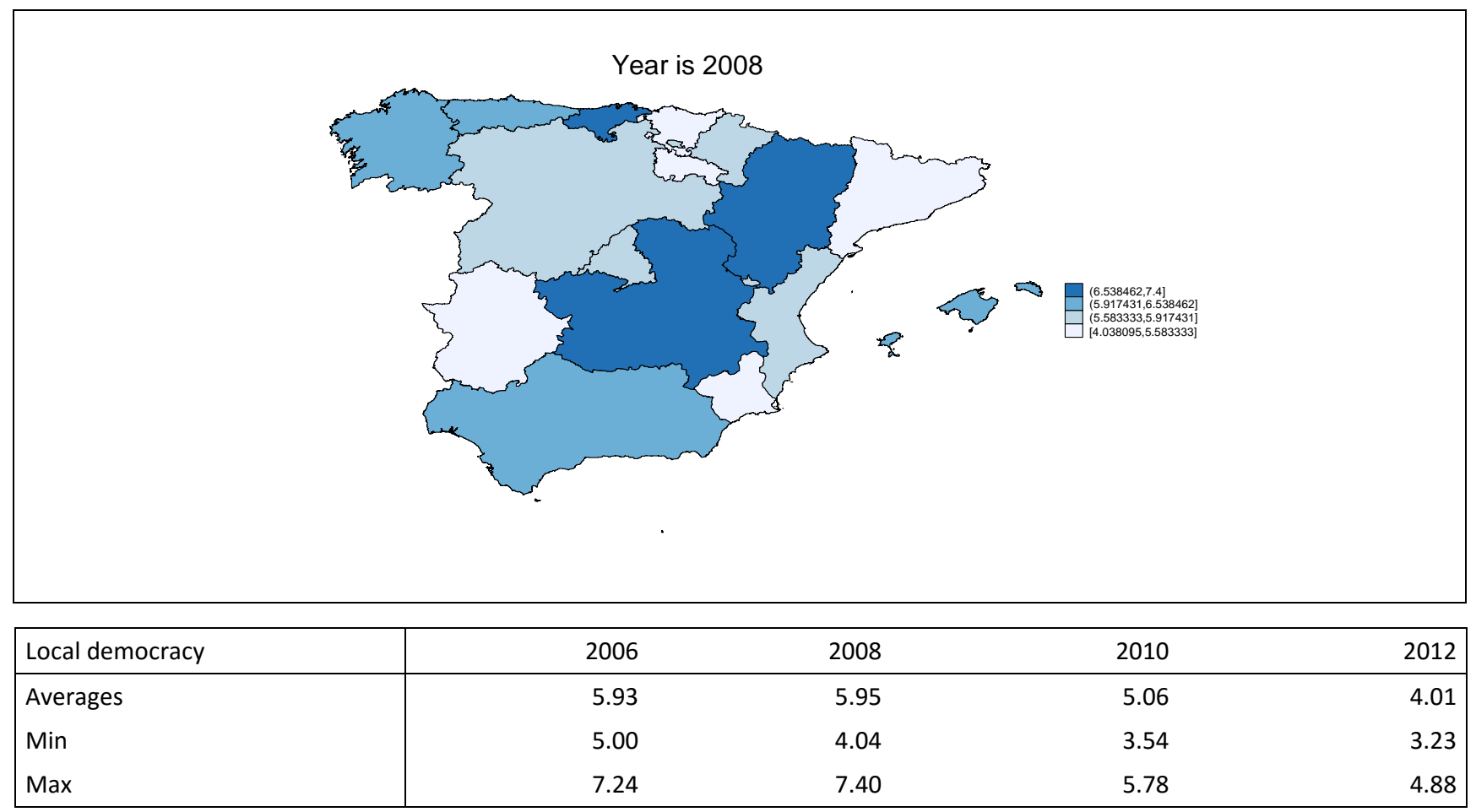


Table 1. Descriptive statistics: job seekers, vacancies and hiring

\begin{tabular}{|l|ccccc|}
\hline $\begin{array}{l}\text { Period } \\
\text { (averages) }\end{array}$ & $\begin{array}{c}\text { No. Job seekers } \\
\text { (stock) }\end{array}$ & $\begin{array}{c}\text { Vacancies } \\
\text { (estimated stock) }\end{array}$ & $\begin{array}{c}\text { Hiring } \\
\text { (flow) }\end{array}$ & $\begin{array}{c}\text { Vacancies } \\
\text { with intermediation }\end{array}$ & $\begin{array}{c}\text { Hiring } \\
\text { with intermediation }\end{array}$ \\
\hline Boom (2/2006-12/2007) & 57749 & 13104 & 7574 & 1559 & 901 \\
Recession (1/2008-6/2009) & 76725 & 14179 & 7784 & 1014 & 556 \\
Rebound (7/2009-6/2011) & 105155 & 13053 & 8754 & 950 & 637 \\
Recession (7/2011-2/2012) & 115722 & 12223 & 8689 & 660 & 469 \\
\hline
\end{tabular}

Table 2. Descriptive statistics: young unemployment (u25), long-term unemployment (uld), high education (he) and turnover

\begin{tabular}{|c|ccc|c|}
\hline period & $\begin{array}{c}\text { u25 } \\
(\%)\end{array}$ & $\begin{array}{c}\text { uld } \\
(\%)\end{array}$ & $\begin{array}{c}\text { he } \\
(\%)\end{array}$ & $\begin{array}{c}\text { Turnover } \\
\text { Job seekers }\end{array}$ \\
\hline Boom (2/2006-12/2007) & 18.69 & 22.19 & 30.99 & 0.1911 \\
Recession (1/2008-/2009) & 28.47 & 21.23 & 31.28 & 0.1847 \\
Rebound (7/2009-6/2011) & 40.59 & 34.40 & 32.46 & 0.1364 \\
Recession(7/2011-2/2012) & 48.58 & 42.69 & 33.64 & 0.1282 \\
\hline
\end{tabular}


Table 3. Estimates over the period: $2 / 2006-2 / 2012$

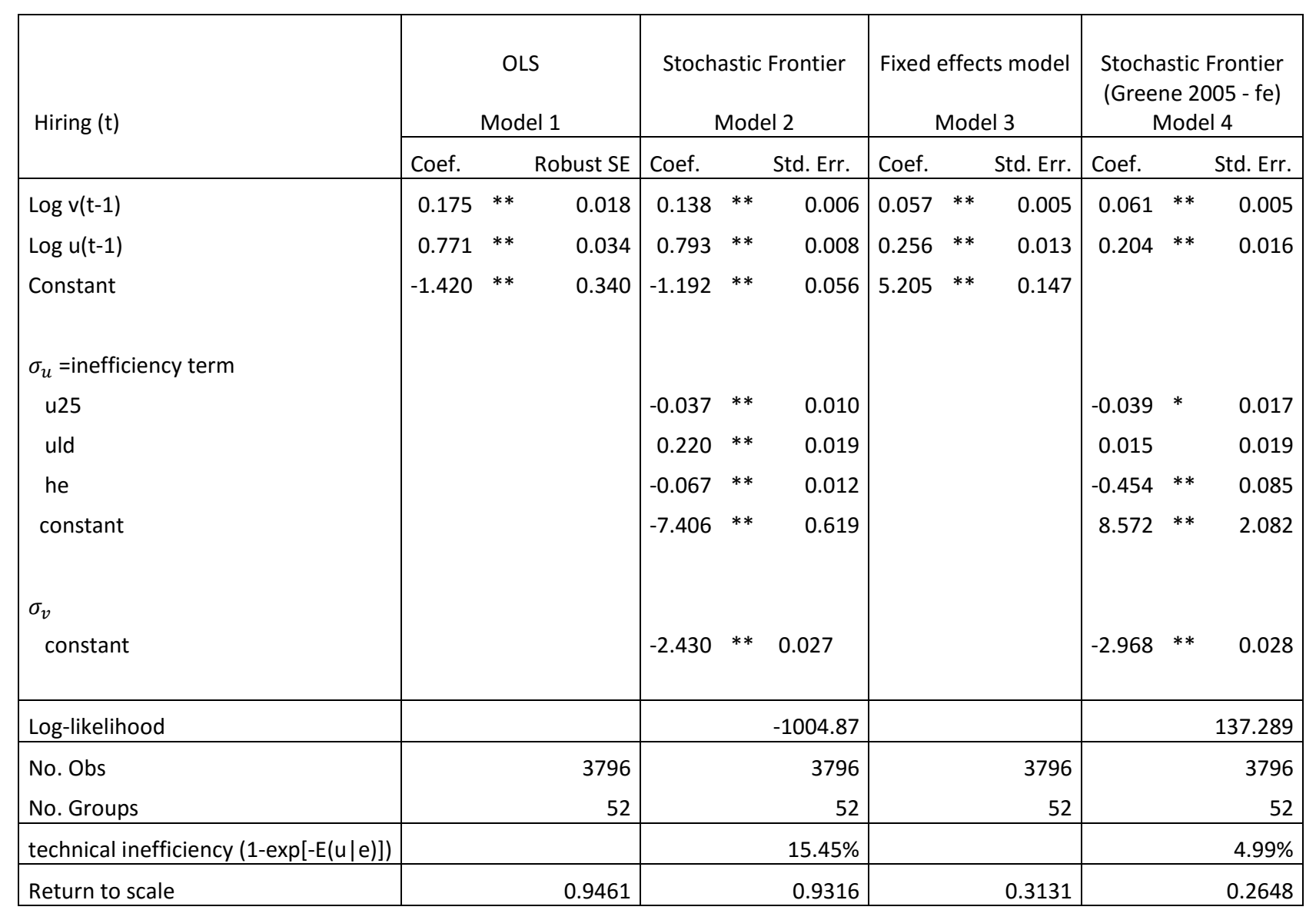


Table 4. Estimates: boom vs recession

\begin{tabular}{|c|c|c|c|c|c|c|c|c|c|}
\hline \multirow[t]{2}{*}{ Hiring (t) } & \multicolumn{3}{|c|}{$\begin{array}{c}\text { Model 4a } \\
\text { Boom } \\
\text { Stochastic Frontier } \\
\text { (Greene } 2005-\mathrm{fe} \text { ) }\end{array}$} & \multicolumn{3}{|c|}{$\begin{array}{c}\text { Model 4b } \\
\text { Recessions/rebound } \\
\text { Stochastic Frontier } \\
\text { (Greene 2005-fe) }\end{array}$} & \multicolumn{3}{|c|}{$\begin{array}{c}\text { Model 4c } \\
\text { Recessions/rebound } \\
\text { Stochastic Frontier } \\
\text { (Greene 2005 - fe) }\end{array}$} \\
\hline & Coef. & & Std. Err. & Coef. & & Std. Err. & Coef. & & Std. Err. \\
\hline $\log v(t-1)$ & 0.037 & $* *$ & 0.008 & 0.085 & $* *$ & 0.006 & 0.081 & $* *$ & 0.006 \\
\hline $\log u(t-1)$ & 0.640 & $* *$ & 0.103 & 0.250 & $* *$ & 0.023 & 0.264 & $* *$ & 0.025 \\
\hline \multicolumn{10}{|l|}{$\sigma_{u}=$ inefficiency term } \\
\hline Crisis dummy & & & & & & & 3.979 & $* *$ & 1.258 \\
\hline Reform 2010 & & & & & & & -3.409 & $* *$ & 1.097 \\
\hline u25 & -0.032 & & 0.020 & -0.044 & & 0.036 & 0.107 & $* *$ & 0.038 \\
\hline uld & 0.025 & & 0.016 & 0.056 & & 0.038 & 0.086 & $* *$ & 0.032 \\
\hline he & -0.036 & $*$ & 0.014 & -0.449 & $* *$ & 0.126 & 0.084 & & 0.057 \\
\hline constant & -1.177 & $*$ & 0.565 & 7.655 & $*$ & 3.167 & -17.564 & $* *$ & 3.900 \\
\hline \multicolumn{10}{|l|}{$\sigma_{v}$} \\
\hline constant & -3.846 & $* *$ & 0.119 & -3.027 & $* *$ & 0.033 & -3.005 & $* *$ & 0.029 \\
\hline Log-likelihood & & & 47.9233 & & & 180.886 & & & 192.885 \\
\hline No. Obs & & & 1196 & & & 2600 & & & 2600 \\
\hline No. Groups & & & 52 & & & 52 & & & 52 \\
\hline technical inefficiency $(1-\exp [-E(u \mid e)])$ & & & $20.69 \%$ & & & $4.62 \%$ & & & $3.03 \%$ \\
\hline Return to scale & & & 0.6769 & & & 0.3343 & & & 0.3452 \\
\hline
\end{tabular}


Table 5. Estimates handling endogeneity

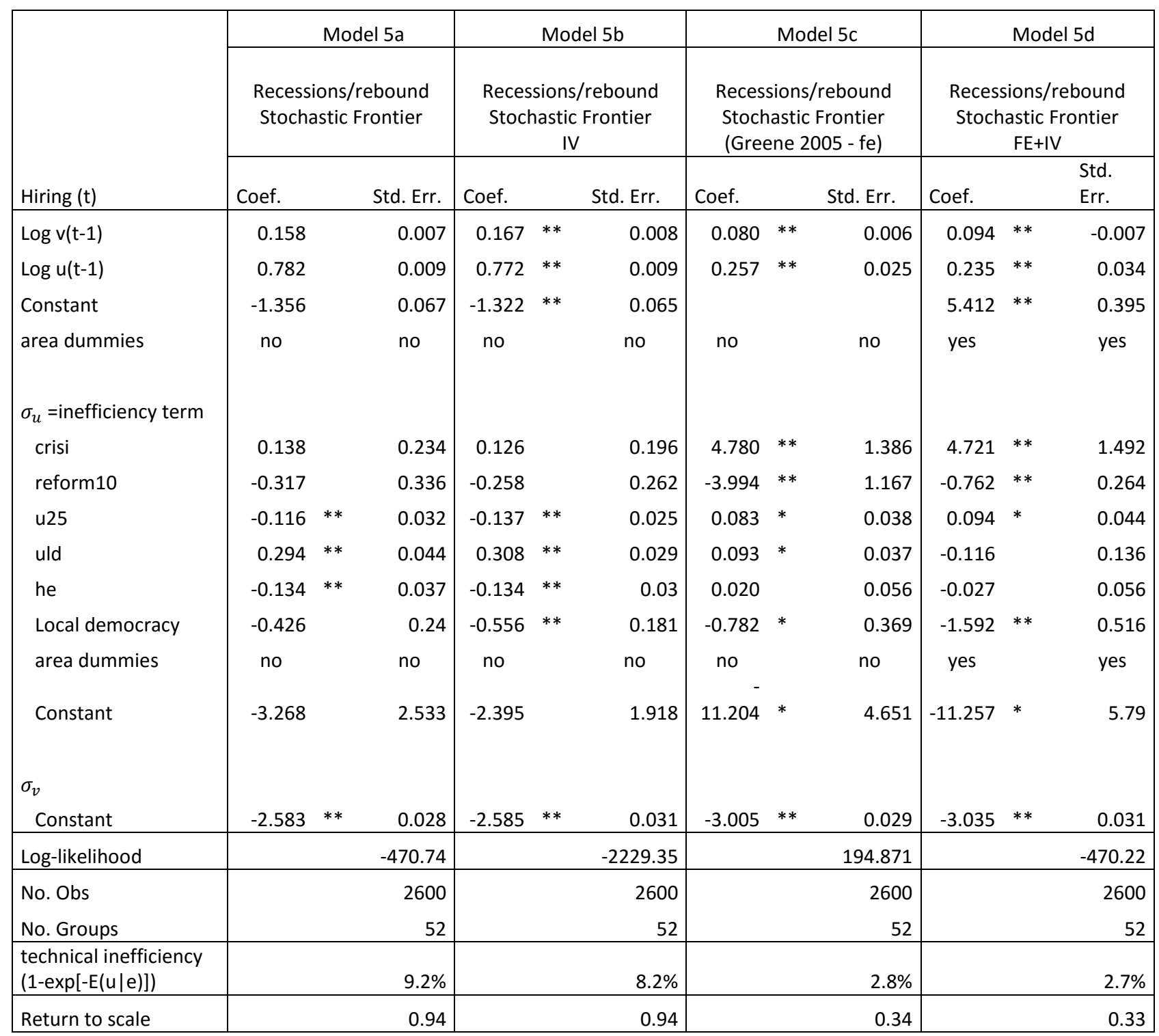


Table 6. Average regional technical inefficiency (1-exp[-E(u|e)]) by period (Models 4, 4a and 4b)

\begin{tabular}{|c|c|c|c|c|c|c|c|}
\hline Region & Inefficiency & boom & $\begin{array}{l}\text { Recessions } \\
\text { /rebound }\end{array}$ & Region & Inefficiency & boom & $\begin{array}{l}\text { Recessions } \\
\text { /rebound }\end{array}$ \\
\hline A CORUÑA & $2.38 \%$ & $19.73 \%$ & $2.27 \%$ & LAS PALMAS & $8.88 \%$ & $17.96 \%$ & $9.65 \%$ \\
\hline ALAVA & $0.08 \%$ & $17.97 \%$ & $0.09 \%$ & LEON & $1.98 \%$ & $20.05 \%$ & $1.78 \%$ \\
\hline ALBACETE & $10.98 \%$ & $21.66 \%$ & $9.61 \%$ & LLEIDA & $2.51 \%$ & $21.63 \%$ & $2.37 \%$ \\
\hline ALICANTE/ALACANT & $4.79 \%$ & $19.79 \%$ & $4.21 \%$ & LUGO & $2.37 \%$ & $20.91 \%$ & $2.27 \%$ \\
\hline ALMERIA & $6.94 \%$ & $24.33 \%$ & $6.05 \%$ & MADRID & $0.37 \%$ & $18.03 \%$ & $0.29 \%$ \\
\hline ASTURIAS & $1.05 \%$ & $19.16 \%$ & $0.85 \%$ & MALAGA & $6.85 \%$ & $19.15 \%$ & $5.97 \%$ \\
\hline AVILA & $2.00 \%$ & $22.32 \%$ & $1.79 \%$ & MELILLA & $7.04 \%$ & $29.83 \%$ & $10.63 \%$ \\
\hline BADAJOZ & $9.23 \%$ & $19.66 \%$ & $8.69 \%$ & MURCIA & $9.43 \%$ & $20.23 \%$ & $8.41 \%$ \\
\hline BALEARS & $18.45 \%$ & $28.49 \%$ & $16.76 \%$ & NAVARRA & $0.45 \%$ & $17.09 \%$ & $0.41 \%$ \\
\hline BARCELONA & $2.50 \%$ & $20.98 \%$ & $2.37 \%$ & OURENSE & $2.37 \%$ & $19.85 \%$ & $2.27 \%$ \\
\hline BURGOS & $2.00 \%$ & $20.39 \%$ & $1.79 \%$ & PALENCIA & $2.01 \%$ & $20.40 \%$ & $1.79 \%$ \\
\hline CACERES & $9.15 \%$ & $19.91 \%$ & $8.62 \%$ & PONTEVEDRA & $2.38 \%$ & $19.63 \%$ & $2.27 \%$ \\
\hline CADIZ & $6.83 \%$ & $18.70 \%$ & $5.97 \%$ & RIOJA & $1.90 \%$ & $20.62 \%$ & $1.27 \%$ \\
\hline CANTABRIA & $0.89 \%$ & $18.63 \%$ & $0.69 \%$ & SALAMANCA & $2.00 \%$ & $20.09 \%$ & $1.79 \%$ \\
\hline CASTELLON/CASTELLO & $4.82 \%$ & $21.85 \%$ & $4.24 \%$ & SEGOVIA & $2.00 \%$ & $19.61 \%$ & $1.79 \%$ \\
\hline CEUTA & $15.96 \%$ & $20.67 \%$ & $16.36 \%$ & SEVILLA & $6.83 \%$ & $20.08 \%$ & $6.00 \%$ \\
\hline CIUDAD REAL & $11.55 \%$ & $24.31 \%$ & $9.87 \%$ & SORIA & $2.01 \%$ & $20.52 \%$ & $1.79 \%$ \\
\hline CORDOBA & $6.93 \%$ & $20.23 \%$ & $6.00 \%$ & STA. C. TENERIFE & $9.13 \%$ & $18.68 \%$ & $9.60 \%$ \\
\hline CUENCA & $11.47 \%$ & $23.63 \%$ & $9.96 \%$ & TARRAGONA & $2.50 \%$ & $21.03 \%$ & $2.37 \%$ \\
\hline GIRONA & $2.51 \%$ & $21.82 \%$ & $2.38 \%$ & TERUEL & $1.40 \%$ & $19.89 \%$ & $1.38 \%$ \\
\hline GRANADA & $6.91 \%$ & $19.97 \%$ & $6.00 \%$ & TOLEDO & $11.05 \%$ & $22.62 \%$ & $9.69 \%$ \\
\hline GUADALAJARA & $10.75 \%$ & $21.74 \%$ & $9.36 \%$ & VALENCIA & $4.74 \%$ & $21.03 \%$ & $4.20 \%$ \\
\hline GUIPUZCOA & $0.08 \%$ & $16.78 \%$ & $0.09 \%$ & VALLADOLID & $2.00 \%$ & $19.70 \%$ & $1.79 \%$ \\
\hline HUELVA & $7.12 \%$ & $22.21 \%$ & $6.09 \%$ & VIZCAYA & $0.08 \%$ & $16.87 \%$ & $0.09 \%$ \\
\hline HUESCA & $1.39 \%$ & $18.94 \%$ & $1.38 \%$ & ZAMORA & $2.00 \%$ & $20.28 \%$ & $1.79 \%$ \\
\hline JAEN & $7.25 \%$ & $26.99 \%$ & $6.17 \%$ & ZARAGOZA & $1.39 \%$ & $19.22 \%$ & $1.38 \%$ \\
\hline
\end{tabular}

